\title{
Crystal structure and biochemical characterization of Chlamydomonas FDX2 reveal two residues that, when mutated, partially confer FDX2 the redox potential and catalytic properties of FDX1
}

\author{
Marko Boehm $^{1} \cdot$ Markus Alahuhta $^{1}$ - David W. Mulder ${ }^{1} \cdot$ Erin A. Peden ${ }^{1} \cdot$ \\ Hai Long ${ }^{2} \cdot$ Roman Brunecky ${ }^{1}$ Vladimir V. Lunin ${ }^{1} \cdot$ Paul W. King ${ }^{1} \cdot$ \\ Maria L. Ghirardi ${ }^{1} \cdot$ Alexandra Dubini $^{1}$ \\ Received: 26 May 2015/Accepted: 14 October 2015/Published online: 3 November 2015 \\ (C) The Author(s) 2015. This article is published with open access at Springerlink.com
}

\begin{abstract}
The green alga Chlamydomonas reinhardtii contains six plastidic [2Fe2S]-cluster ferredoxins (FDXs), with FDX1 as the predominant isoform under photoautotrophic growth. FDX2 is highly similar to FDX1 and has been shown to interact with specific enzymes (such as nitrite reductase), as well as to share interactors with FDX1, such as the hydrogenases (HYDA), ferredoxin:NAD(P) reductase I (FNR1), and pyruvate:ferredoxin oxidoreductase (PFR1), albeit performing at low catalytic rates. Here we report the FDX2 crystal structure solved at $1.18 \AA$ resolution. Based on differences between the Chlorella fusca FDX1 and C. reinhardtii FDX2 structures, we generated and purified point-mutated versions of the FDX2 protein and assayed them in vitro for their ability to catalyze hydrogen and NADPH photo-production. The data show that structural differences at two amino acid positions contribute to functional differences between FDX1 and FDX2, suggesting that FDX2 might have evolved from FDX1 toward a different physiological role in the cell. Moreover, we demonstrate that the mutations affect both the midpoint potentials of the FDX and kinetics of the FNR reaction, possibly due to altered
\end{abstract}

Marko Boehm and Markus Alahuhta authors have contributed equally to the work.

Electronic supplementary material The online version of this article (doi:10.1007/s11120-015-0198-6) contains supplementary material, which is available to authorized users.

Alexandra Dubini

alexdubini@yahoo.com; alexandra.dubini@nrel.gov

1 Biosciences Center, National Renewable Energy Laboratory, Mail Stop: 3313, 15013 Denver West Parkway, Golden, CO 80401, USA

2 Computational Science Center, National Renewable Energy Laboratory, 15013 Denver West Parkway, Golden, CO 80401, USA binding between FDX and FNR. An effect on $\mathrm{H}_{2}$ photo-production rates was also observed, although the kinetics of the reaction were not further characterized.

Keywords Ferredoxin - Chlamydomonas - Structure · Interaction $\cdot \mathrm{NADPH} \cdot$ Hydrogen photo-production

$\begin{array}{ll}\text { Abbreviations } & \\ \text { CD } & \text { Circular dichroism } \\ \text { DCMU } & \begin{array}{l}\text { 3-(3,4-Dichlorophenyl)-1,1- } \\ \text { dimethylurea })\end{array} \\ \text { DCPIP } & \text { 2,6-Dichlorophenolindophenol } \\ \text { DMSO } & \text { Dimethyl sulfoxide } \\ \text { DTT or NaDT } & \text { Sodium dithionite } \\ \text { EPR } & \text { Electron paramagnetic resonance } \\ \text { FAD } & \text { Flavin adenine nucleotide } \\ \text { FDX } & \text { Ferredoxin } \\ \text { FNR } & \text { Ferredoxin/NADP(H) oxidoreductase } \\ \text { FPLC } & \text { Fast protein liquid chromatography } \\ \text { GST } & \text { Glutathione S-transferase } \\ \text { HYDA } & \text { Algal hydrogenase } \\ \text { NADP(H) } & \text { Nicotinamide adenine dinucleotide } \\ & \text { phosphate-oxidase } \\ \text { PCR } & \text { Polymerase chain reaction } \\ \text { PFR1 } & \text { Pyruvate/ferredoxin oxidoreductasePDB, } \\ & \text { protein database } \\ \text { RT } & \text { Room temperature } \\ \text { TEV } & \text { Tobacco etch virus protease }\end{array}$

Introduction

Ferredoxins (FDXs) are small, ubiquitous proteins that typically contain iron-sulfur clusters and mediate electron shuttling among multiple metabolic pathways. The green 
alga Chlamydomonas reinhardtii (Chlamydomonas throughout) contains six genes that encode for chloroplastlocalized ferredoxins. These proteins have been categorized into three separate groups, according to the plant nomenclature: FDX1 and FDX5 belong to the photosynthetic category (or leaf type), FDX2 belong to the non-photosynthetic group (or root type), and FDX3, FDX4, and FDX6 are divergent, being more closely related to bacterial FDXs (Terauchi et al. 2009). In their oxidized state, FDXs display absorption maxima in the visible region at about 330, 420, and $464 \mathrm{~nm}$, and their redox potentials are very negative; FDX1, for example, is centered at around $-398 \mathrm{mV}$ (Wada et al. 1974; Orme-Johnson 1973; Matsubara and Sasaki 1968; Hutson et al. 1978; Hase et al. 1976). FDXs harbor a $\mathrm{CX}_{4} \mathrm{CX}_{2} \mathrm{CX}_{\mathrm{n}} \mathrm{C}$ motif required for [2Fe2S]-cluster ligation and form specific electrostatic complexes with a variety of interacting enzymes, using carboxyl side-chain groups of conserved amino acids that generally interact with lysine or arginine counterparts on the binding partner.

As electron shuttles, Chlamydomonas FDXs are particularly important for hydrogen production, because they are the natural electron donor to the hydrogenases in vivo. Chlamydomonas contains two [FeFe]-hydrogenase enzymes, $C r H Y D A 1$ and $C r H Y D A 2$, which catalyze the formation of hydrogen from two electrons and two protons, either under light-anoxic or dark-anoxic conditions (Ghirardi et al. 2000; Harris 2009). FDXs represent a branch point for three hydrogen production pathways (Meuser et al. 2012; Winkler et al. 2010): the PSII dependent, PSII independent, and fermentative.

To further characterize the role of the algal FDXs, Peden et al. (2013) identified specific targets for each of the six Chlamydomonas FDXs and assessed CrFDX1 and CrFDX2 specificity toward selected metabolic pathways. Using yeast two-hybrid and pull-down assays, they detected binding partners for the two $\mathrm{CrFDXs}$ and confirmed that $C r F D X 2$ can also interact with common $C r F D X 1$ interaction partners. CrFDX2 amino acid sequence is highly homologous to that of $C r F D X 1$ (67\% identity for the mature proteins), and it contains conserved residues that are known to be important for interactions with CrFDX1 enzyme targets (Winkler et al. 2009b). This sequence conservation might explain why $\mathrm{CrFDX} 2$ participates in electron-transfer reactions with similar redox partners as $C r F D X 1$, although at lower rates. Both proteins contain three highly conserved, negatively charged, solvent-exposed regions that were proposed to be responsible for mediating protein-protein interactions in FDXs (Kameda et al. 2011). Typically, these regions form a highly conserved structure that facilitates cluster insertion to the apo-protein and electron transfer to/from the mature protein (Bertini et al. 2002; Kameda et al. 2011). Four conserved amino acid residues present in the two $\mathrm{CrFDXs}$ specifically contribute to electron donor/acceptor selectivity in vivo (Terauchi et al. 2009). Indeed, $\mathrm{CrFDX} 2$ has recently been shown to mediate electron transfer (although not as efficiently as $C r$ FDX1) to known $C r F D X 1$ interaction partners, i.e., CrFNR1, CrHYDA1, and CrPFR1, (Noth et al. 2012; Peden et al. 2013; Terauchi et al. 2009; van Lis et al. 2013). However, it is unknown whether or under which conditions this happens in vivo.

Structural models have predicted differences in surface charge distribution on the two $C r F D X s$, which may explain CrFDX1's more negative redox potential (-398 vs -321 mV for CrFDX2) (Galván and Márquez 1985; Terauchi et al. 2009). These distinct physical characteristics might determine their interaction specificity and influence the binding of various electron acceptors/donors to each protein (Terauchi et al. 2009). Notably, CrFDX2 lacks a phenylalanine (F62) residue that may be required for the proper interaction of $C r F D X 1$ with $C r H Y D A$ (Winkler et al. 2009a) and possibly with CrFNR1 (Hurley et al. 1997; Mayoral et al. 2005); it also lacks a C-terminus tyrosine residue, Y95, present in $C r F D X 1$. The lower capability of $C r$ HYDA1 to generate hydrogen using $C r F D X 2$ as the electron donor might be indicative not only of their different redox potentials but also of different interaction mechanisms between $C r$ HYDA 1 and either $C r F D X 1$ or $C r F D X 2$.

In an effort to better define these interactions and the function of $C r F D X 1$ and $C r F D X 2$, we over-expressed the two proteins in E. coli. The mature versions of these proteins were purified, used for crystallography studies, and characterized by different types of spectroscopic techniques (see supplemental data 1, 2, 3, and 4). Here we report the first 3D structure of a Chlamydomonas ferredoxin, $\mathrm{CrFDX} 2$, at atomic resolution of $1.18 \AA$. The $C r F D X 2$ folding motif is similar to that of previously published plant-type FDX structures from other organism (Bes et al. 1999; Fish et al. 2005), one of which represents a FDX1 type from Chlorella fusca $(C f)$, with high sequence homology to the noncrystallized $C r F D X 1$. Based on the high degree of similarity between $C f$ and $C r$ FDX1, comparison with the $C r$ FDX2 structure, and published data, we selected two amino acid residues present on the interaction surface of $C r F D X 1$ with FNR and hydrogenase (but absent or present as a different residue on $C r F D X 2$ ). We mutated $C r F D X 2$ F62 to M62 (the equivalent residue in $C r F D X 1)$ and inserted Y95 into CrFDX2 through site-directed mutagenesis. We show that mutations that replace these residues with those found in $C r F D X 1$ lower $C r F D X 2$ 's midpoint redox potential to values closer to that of $C r F D X 1$, indicating that these residues contribute to functional differences between $C r F D X 1$ and CrFDX2. The major observed difference consisted of altered midpoint redox potential of the FDX cluster, resulting in changes in its catalytic efficiency with respect to FNR-mediated $\mathrm{NADP}^{+}$reduction, as well as alterations in the 
maximum rates of hydrogenase-catalyzed $\mathrm{H}_{2}$ photo-production in vitro.

\section{Materials and methods}

\section{Plasmid construction}

We constructed several over-expression plasmids for all the mature, codon-optimized (Mr. Gene, Germany) versions of the Chlamydomonas FDX proteins, using a modified version of the pRSETA vector (Life Technologies, USA; Michoux et al. 2010) as the backbone. For the pulldown experiments, we used N-terminal His-tagged $C r$ FDX 1 and $C r$ FDX2 proteins that were expressed from the pRESTA His-FDX1 and pRESTA His-FDX 2 expression constructs, respectively. For this, the $C r F D X 1$ and CrFDX2 coding sequences were amplified using FDX1 primers (Peden et al. 2013) and the following FDX2 primers: FDX2-Fw GGATCCTTCAAAGTCACCTTCAAAA CCCCAAAAGGTG-3' and FDX2-Rev 5'-ACATCGTCA TTTTAACCGATCAAGAATCAAAATTGTGAGAAT TC-3. The amplified gene sequences were cloned into the BamHI and EcoRI restriction sites on the vector. The tobacco etch virus protease (TEV)-cleaved versions of the $C r$ FDX 1 and $C r F D X 2$ proteins were expressed as HisGST-TEVcs-FDX1 and His-GST-TEVcs-FDX2 fusion proteins and contained a linker sequence (Yacoby et al. 2012) between the His-GST tandem affinity tag and the FDX sequence. These versions were used for UV/Vis and EPR spectroscopy. The cleaved versions of the $\mathrm{CrFDX} 1$ and $\mathrm{Cr} F \mathrm{FX} 2$ proteins used for $\mathrm{CD}$ spectroscopy that yielded $\mathrm{CrFDX} 2$ crystals for X-ray crystallography were expressed as FDX1-TEVcs-GST-His and FDX2-TEVcs-GST-His fusion proteins that contained the same linker sequence (Yacoby et al. 2012) between the FDX and the GST-His tandem affinity tag. To generate the expression constructs for the point-mutated $C r F D X 2 \mathrm{~s}(\mathrm{M} 62 \mathrm{~F}, \nabla 95 \mathrm{Y}$ and M62F/ $\nabla 95 \mathrm{Y})$, the C-terminal-encoding fragment of the $\mathrm{CrFDX} 2$ protein was excised from the His-GST-TEVcs-FDX2 construct using HincII and EcoRI. Subsequently, digested PCR fragments generated with the following primers replaced the excised fragment: (A) CrFDX2 M62F: Fw 5'-GCGGTCGA CCAATCCGACCAAAACTTTTTGGACGAAGATCAA TTG-3', (B) $C r$ FDX2 M62F Rv: 5'-GGAATTCTCACAAT TTTGATTCTTGATC.

GGTTAAAATGACGATGT-3'，(C) $\quad C r$ FDX2 $\quad \nabla$ Y95 Fw: 5'-GCGTACTGTCGACCAATCCGACCAA.

AACATG-3', and (D) CrFDX2 $\nabla$ Y95 Rev: 5'-GAAT TCTCAGTACAATTTTGATTCTTGATCGGTTAAAAT GACGATGT- $3^{\prime}$. The appropriate primer combinations were used to introduce the two point mutations into the WT FDX2.

\section{Protein purification}

The $C r F D X 1$ and $C r F D X 2$ over-expression plasmids were transformed into E. coli KRX cells (Promega, USA). For expression in Terrific Broth with $200 \mu \mathrm{g} / \mathrm{ml}$ Ampicillin (TB; VWR, USA), a starter culture was grown overnight at $37^{\circ} \mathrm{C}$ and diluted $1: 100$ in a $100-\mathrm{ml}$ TB subculture the following morning. After the subculture had reached an OD600 of $\sim 0.7,10 \mathrm{ml}$ of it were used to inoculate $1 \mathrm{~L}$ of TB media supplemented with $0.4 \%$ (w/v) glycerol. At OD600 of $~ 0.7$, IPTG and Ferric ammonium citrate were added to final concentrations of $1 \mathrm{mM}$ and $0.05 \%$ (w/v), respectively, (Peden et al. 2013). The cells were harvested and resuspended in $100 \mathrm{ml}$ lysis buffer $(25 \mathrm{mM}$ Tris $\mathrm{pH}$ 7.9, $100 \mathrm{mM} \mathrm{NaCl}$, and $1 \mathrm{mM}$ DTT) for breakage. The supernatant obtained after centrifugation was incubated for $1 \mathrm{~h}$ at $4{ }^{\circ} \mathrm{C}$ with $20 \mathrm{ml}$ of glutathione affinity resin (Genscript, USA). After the incubation period, the resin was washed with 15 column volumes (CV) of lysis buffer or until the wash solution became clear and colorless. Protein elution was performed with $2 \times \mathrm{CV}$ of elution buffer $(25 \mathrm{mM}$ Tris $\mathrm{pH}=7.9,100 \mathrm{mM} \mathrm{NaCl}$, and $10 \mathrm{mM}$ reduced glutathione). $20 \mathrm{mg}$ of TEV-His (His-tag purified from pRK193 (Kapust et al. 2001; Addgene, USA) were added to cleave the affinity tag. After a 2-h incubation period at RT, the sample was applied to a TALON Cobalt affinity chromatography column ( $\sim 20 \mathrm{ml}$ resin (Clontech, USA) packed in a XK16/20 (GE Healthcare column) coupled to an Äkta FPLC (GE Healthcare, USA), see supplemental Fig. 1. We used $25 \mathrm{mM}$ Tris $\mathrm{pH} 7.0$, $100 \mathrm{mM} \mathrm{NaCl}$, and $5 \%(\mathrm{v} / \mathrm{v})$ glycerol as the running buffer at a flow rate of $5-10 \mathrm{ml} \mathrm{min}{ }^{-1}$. The flow-through was collected and loaded onto a HiLoad ${ }^{\mathrm{TM}}$ 26/60 Super$\operatorname{dex}^{\mathrm{TM}} 75$ prep grade (GE Healthcare, USA) following the purification method developed by Peden et al. (2013). The iron content was determined using a colorimetric assay described (Winkler et al. 2009b), which uses ferrozine under reductive conditions after digestion of the protein in $4.5 \%(w / v) \mathrm{KMnO} 4$ and $1.2 \mathrm{~N} \mathrm{HCl}$.

\section{Protein crystallization}

$\mathrm{CrFDX} 2$ protein crystals were obtained by the sitting drop vapor diffusion method, using a 96-well plate with Crystal Screen HT (Hampton Research, USA). Fifty $\mu \mathrm{L}$ of well solution were added to the reservoirs and drops were made with $0.2 \mu \mathrm{L}$ of well and $0.2 \mu \mathrm{L}$ of protein solution using a Phoenix crystallization robot (Art Robbins Instruments, USA). Protein crystals grew at $20^{\circ} \mathrm{C}$ in $0.1 \mathrm{M}$ HEPES $\mathrm{pH}$ 7.0 and $3.2 \mathrm{M}$ ammonium sulfate as the well solution. The protein solution contained $17.3 \mathrm{mg} / \mathrm{ml}$ of protein in $25 \mathrm{mM}$ Tris $\mathrm{pH}$ 7.0, $200 \mathrm{mM} \mathrm{NaCl}$, and $5 \%(\mathrm{v} / \mathrm{v})$ glycerol. 
A

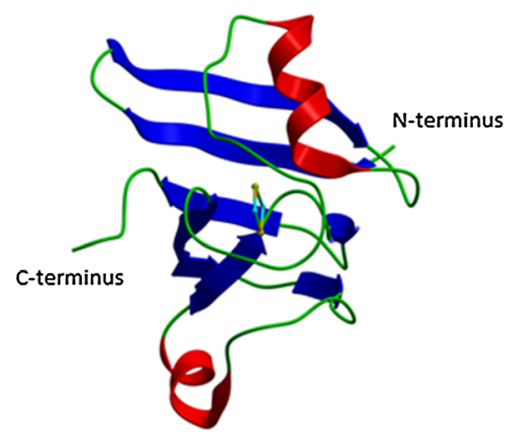

B

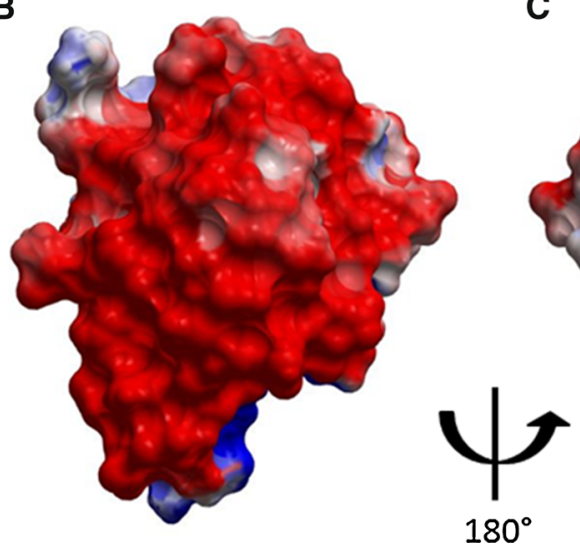

C

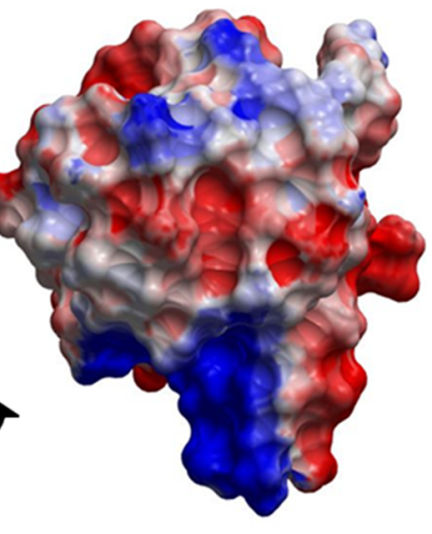

Fig. $1 \mathrm{CrFDX} 2$ secondary structure and surface charge distribution models. a Ribbon diagram of the $C r F D X 2$ structure with the [2Fe2S] cluster. $\mathrm{N}$ - and $\mathrm{C}$-termini are indicated. Loops are shown as green ribbons; $\alpha$-helices are in red and $\beta$-strands in blue; the [2Fe2S] cluster is shown in ball and stick format, with sulfur in yellow and iron atoms in cyan. b, c Electrostatic surfaces charges are shown in red

\section{Data collection and processing}

The $C r F D X 2$ protein crystal was flash-frozen in a nitrogen gas stream at $100 \mathrm{~K}$ before data collection, using an inhouse Bruker $\times 8$ MicroStar X-Ray generator with Helios mirrors and Bruker Platinum $135 \mathrm{CCD}$ detector. A well solution containing $5 \%(\mathrm{v} / \mathrm{v})$ glycerol and $5 \%(\mathrm{v} / \mathrm{v})$ ethylene glycol was added into the drop before freezing to prevent ice formation. Data were indexed and processed with the Bruker suite of programs version 2011.2-0 (Bruker AXS, USA).

\section{Structure solution and refinement}

Intensities obtained from data processing (derived from diffraction intensities) were converted into structure factors and $5 \%$ of the reflections were flagged for Rfree calculations using the programs SCALEPACK2MTZ, ctruncate, MTZDUMP, Unique, CAD, FREERFLAG, and MTZUTILS from the CCP4 package (Winn et al. 2011). The program MrBUMP version 0.6.1 (Winn et al. 2011) automatically solved the structure using the FASTA (Pearson and Lipman 1988) and MOLREP (Vagin and Teplyakov 2010) programs for sequence searches and molecular replacement. Refinement and manual correction were performed using the REFMAC5 (Murshudov et al. 2011) version 5.7.0032 and the Coot (Emsley et al. 2010) version 0.6.2 programs. The MOLPROBITY method (Chen et al. 2010a) was used to analyze the Ramachandran plot, and root mean square deviations (rmsd) of bond lengths and angles were calculated from ideal values of Engh and Huber stereochemical parameters (Engh and Huber 1991). The Wilson B-factor was calculated using the ctruncate version 1.5.1, and average B-factors were calculated using (negative) and blue (positive). Panel $B$ is shown in the same orientation as Panel $A$ and represents a straight-on view of the [2Fe2S] cluster. Panel $C$ is rotated $180^{\circ}$ with respect to panels $A$ and $B$. The orientation chosen here highlights the different-charged region of $C r F D X 2$ with the red region being the area of $C r F N R / C r H Y D A 1$ interaction

the ICM version 3.7-2a program (Molsoft LLC, USA). Coot, PyMOL (http://www.pymol.org), and ICM (http:// www.molsoft.com) were used for comparing and analyzing structures. Figure 1 was done using ICM and PyMOL was used to make Fig. 2. The data collection and refinement statistics are shown in Table 1.

\section{Isolation of thylakoids}

In order to generate the thylakoids membrane for the $\mathrm{H}_{2}$ and NADP assays, Chlamydomonas cells were harvested from cultures grown in Tris/Acetate/Phosphate medium (TAP) (pH 7.2) (Harris 2009). Algal cultures were maintained at $25{ }^{\circ} \mathrm{C}$, vigorously bubbled with air enriched with $3 \%(\mathrm{v} / \mathrm{v}) \mathrm{CO}_{2}$, stirred using a magnetic stirrer bar, and illuminated with continuous light of $80 \mu \mathrm{mol}$ photon $\mathrm{m}^{-2}$ $\mathrm{s}^{-1}$. These cells were then washed with $1 / 5$ volume of buffer 1 (containing $10.35 \mathrm{M}$ sorbitol, $20 \mathrm{mM}$ HEPES, pH 7.5, $2.0 \mathrm{mM} \mathrm{MgCl} 2$ ) and repellet as above. The cells were broken using a french press and the thylakoids were pelleted at $40,000 \times \mathrm{G}$ (for $20 \mathrm{~min}$ at $4{ }^{\circ} \mathrm{C}$ ). The final thylakoids were resuspended in equal or greater volume of buffer 1 , homogenized and spinned at $1200 \times \mathrm{G}$ for $30 \mathrm{~s}$ to pellet unbroken cells. The supernatant was removed and the pelletted thylakoids stored at $-80{ }^{\circ} \mathrm{C}$ at with a final concentration of $1.0 \mathrm{mg} \mathrm{Chl}^{-1} \mathrm{ml}^{-1}$.

\section{Hydrogen photo-production}

A master mix was prepared for the hydrogen photo-production assay as follows (amount per assay): $900 \mathrm{ml}$ buffer A $\left(50 \mathrm{mM}\right.$ tris- $\mathrm{HCl} \mathrm{pH} 7.4,3.35 \mathrm{mg} \mathrm{ml}^{-1}$ bovine serum albumin, $10 \mathrm{mM} \mathrm{MgCl}_{2}$, and $200 \mathrm{mg} \mathrm{ml}^{-1}$ sucrose), $5 \mu \mathrm{L}$ of DCPIP $(0.01 \mathrm{mM}$ in buffer A), $10 \mu \mathrm{L}$ of DCMU 

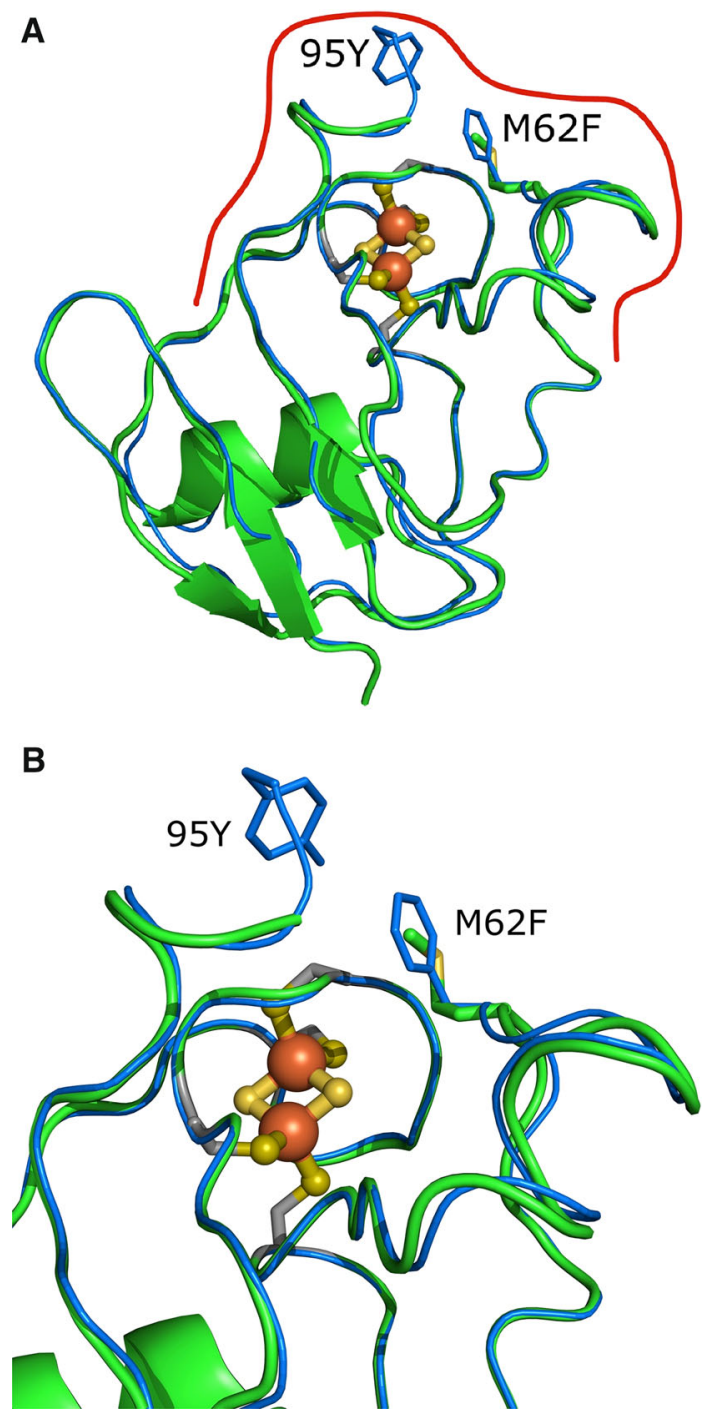

Fig. $2 C r$ FDX2 binding interface with $C r$ HYDA1/CrFNR1 and point mutations. a Overall view of $C r F D X 2$ superimposed with $C f F D X 1$. Mutations and the approximate binding interface area indicated by a red line. $\mathbf{b}$ Closer view of the mutations. Coloring The backbone of $\mathrm{CrFDX} 2$ is shown as green ribbon and CfFDX1 backbone is shown in blue; oxygen atoms are red, nitrogen atoms are blue, sulfur atoms are yellow, and the coordinating cysteine side-chain carbons are colored gray. The $[2 \mathrm{Fe} 2 \mathrm{~S}]$ cluster is shown in ball and stick, with sulfur in yellow and iron in orange. The main chains of the residue stick representations have been hidden for clarity

(0.3 $\mathrm{mM}$ in DMSO), $10 \mu \mathrm{L}$ of sodium ascorbate $(1 \mathrm{M})$, $10 \mu \mathrm{L}$ glucose oxidase $(30 \mathrm{mg} / \mathrm{ml}$ in buffer $\mathrm{A}), 50 \mu \mathrm{L}$ glucose $(1 \mathrm{M}), 10 \mu \mathrm{L}$ catalase $\left(10 \mathrm{mg} \mathrm{ml}^{-1}\right.$ in buffer $\left.\mathrm{A}\right)$, $50 \mu \mathrm{L} 96 \%$ (v/v) ethanol, and $100 \mathrm{nM}$ HYDA1 hydrogenase (in buffer A), as described previously (24). All solutions had been previously degassed and were mixed inside a MBRAUN glove box in a $100 \% \mathrm{~N}_{2}$ atmosphere. FDX was placed in $9-\mathrm{ml}$ serum vials containing the master mix to a final concentration of $10 \mathrm{mM}$. After addition of
Table 1 X-ray data collection and refinement statistics for $\mathrm{CrFDX} 2$ crystal structure

\begin{tabular}{ll}
\hline Data collection & \\
\hline Space group & $\mathrm{P} 1$ \\
Unit cell $\left(\AA{ }^{\circ}\right)$ & \multicolumn{1}{c}{$c=25.429, b=26.458}$, \\
& $\alpha=102.56, \beta=104.35$, \\
& $\gamma=100.30$
\end{tabular}

Statistics for the highest resolution bin are in parenthesis

${ }^{\text {a }}$ Rint $=\sum|I-<I>| / \sum|I|$ where $I$ is the intensity of an individual reflection and $\langle I\rangle$ is the mean intensity of a group of equivalents, and the sums are calculated over all reflections with more than one equivalent measured

b Chen et al. (2010b)

c Chen et al. (2010a)

Chlamydomonas thylakoids to a final concentration of $25 \mathrm{mg} \mathrm{ml}^{-1}$ chlorophyll in the dark, $1.2 \mathrm{ml}$ of the master mix were transferred to serum vials. The vials were sealed with rubber septa and wrapped in aluminum foil. A zero time-point sample was taken, the vial was unwrapped, and illuminated at $400 \mu \mathrm{mol}$ photons $\mathrm{m}^{-2} \mathrm{~s}^{-1}$ generated by a LED light source (2000 W Diamond Series, www.advan cedLEDlights.com). Hydrogen in the head-space was measured at different time points by a gas chromatograph (400 $\mu \mathrm{l}$ injection volume), and the resulting hydrogen production rates were calculated using data from three 
replicate samples for each FDX tested $\left(\mu \mathrm{mol} \mathrm{H}_{2} \mu \mathrm{g}\right.$ $\left.\mathrm{Chl}^{-1} \mathrm{~h}^{-1}\right)$.

\section{NADPH photo-production}

Initially, three solutions were prepared: (a) a buffer master mix containing (for each FDX/concentration combination) $1 \mu \mathrm{l}$ of DCMU (0.3 mM in DMSO), $2.5 \mu \mathrm{l}$ of DCPIP $(0.01 \mathrm{mM}), 5 \mu \mathrm{l}$ of sodium ascorbate $(1 \mathrm{M})$, Chlamydomonas thylakoids to a Chl concentration of $50 \mu \mathrm{g} \mathrm{ml}^{-1}$ (in the final assay) and buffer A (see above) to a total volume of $268 \mu \mathrm{l}$ per buffer master mix; (b) a protein mix (final volume of $208 \mu \mathrm{l}$ ) containing $0.5 \mu \mathrm{M}$ Chlamydomonas FNR1 (expressed in and purified from E. coli) and various concentrations of FDXs (FDX1, FDX2, FDX2 M62F, FDX2 $\nabla 95 \mathrm{Y}$, and FDX2 M62F/ $795 \mathrm{Y}$ ), and (c) a $0.04 \mathrm{mM} \mathrm{NADP}^{+}$solution. For each assay, $8 \mu \mathrm{l}$ of the $\mathrm{NADP}^{+}$solution were placed in a well of a 96-well plate. Then, in the dark, $208 \mu \mathrm{l}$ of the buffer master mix were added to each protein mix and $130 \mu \mathrm{l}$ of this mixture were added to three separate wells (triplicate samples). The plate was kept in the dark ( $t=0$ was taken) and then illuminated at $300 \mu \mathrm{mol}$ photons $\mathrm{m}^{-2} \mathrm{~s}^{-1}$ from an LED light source (2000 W Diamond Series, www.advancedLEDlights.com). Further absorbance measurements were taken at various time points and recorded by the Infinite M200Pro plate reader (Tecan, USA). NADPH production rates $(\mu \mathrm{mol}$ NADPH $\mu \mathrm{g} \mathrm{Chl}^{-1} \mathrm{~h}^{-1}$; for FNR1 at $1 \mathrm{mM}$ in a final volume of $1 \mathrm{ml}$ ) were calculated based on a NADPH standard curve to determine the amount of NADPH produced in the assay (assay volume is $138 \mu \mathrm{l}$ ). Subsequently, the inverse of the rates were plotted over the inverse of the FDX concentrations in a Lineweaver-Burk plot and both $K_{\mathrm{m}}$ and $V_{\max }$ values were calculated for three replicates of each FDX and concentration combinations.

\section{EPR monitored redox titrations}

Potentiometric titrations of FDX2 mutants and FDX2 for reference were carried out anaerobically in a MBraun box $\left(\mathrm{N}_{2}\right.$ atmosphere, $\left.25^{\circ} \mathrm{C}\right)$ using an ORP triode electrode (internal $\mathrm{Ag} / \mathrm{AgCl}$ reference, platinum sensor, Thermo Scientific 9678BNWP). The electrode was connected via a $\mathrm{BNC}$ cable to a $\mathrm{pH}$ meter (Oakton) operating in relative $\mathrm{mV}$ mode and calibrated to a standard solution (Orion 967901). All values were adjusted $+200 \mathrm{mV}$ and reported versus the normal hydrogen electrode (NHE) potential. The reaction was carried out in a custom vessel (Allen Scientific Glass, Boulder $\mathrm{CO}$ ) with magnetic stirring using a similar reductive titration procedure as described previously (Usselman et al. 2008). NaDT was used as the reductant and added in $2 \mathrm{uL}$ increments ( $2 \mathrm{mM}$ stock) with a Hamilton repeating dispenser to the protein $(2-5 \mathrm{mg} / \mathrm{mL})$ buffer solution (50 mM Tris $\mathrm{pH} 7.8,100 \mathrm{mM} \mathrm{NaCl}, 20 \%$ glycerol). The protein buffer solution was supplemented with a redox mediator cocktail ( $3 \mu \mathrm{M}$ final concentration) to allow for fast equilibrium between protein and reductant (Dutton 1978). The cocktail consisted of indigo disulfonate $\left(E_{\mathrm{m}}=-255 \mathrm{mV}\right.$ vs NHE), phenosafranine $\left(E_{\mathrm{m}}=-255\right.$ $\mathrm{mV}$ vs NHE), benzyl viologen $\left(E_{\mathrm{m}}=-361 \mathrm{mV}\right.$ vs NHE), and methyl viologen $\left(E_{\mathrm{m}}=-440 \mathrm{mV}\right.$ vs NHE). Samples at poised redox potentials were removed from the vessel after several minutes of equilibration following $\mathrm{NaDT}$ addition at roughly $20 \mathrm{mV}$ increments and transferred to $4 \mathrm{mM}$ EPR tubes (Wilmad LabGlass). EPR tubes were sealed with septa and frozen in liquid nitrogen.

EPR spectra were recorded on a Bruker ELEXSYS E500 CW X-band spectrometer system outfitted with an Oxford Instruments cryostat and temperature controller and cylindrical (SHQ) Bruker resonator. Spectra were collected at optimal power and temperature settings $(1.0 \mathrm{~mW}$, $23 \pm 3 \mathrm{~K})$ as determined from power saturation and temperature analysis of reduced wild-type samples (Supplemental Fig. 3). Other spectrometer settings were as follows: microwave frequency, $9.385 \mathrm{GHz}$; modulation frequency, $100 \mathrm{kHz}$; modulation amplitude, $10.0 \mathrm{G}$; and time constant, $327.68 \mathrm{~ms}$. Simulations of the spectra were carried out in EasySpin (Stoll and Schweiger 2006).

To determine the midpoint potential $\left(E_{\mathrm{m}}\right)$ of the $[2 \mathrm{Fe} 2 \mathrm{~S}]^{2+/ 1+}$ cluster, plots of signal amplitude of the reduced $[2 \mathrm{Fe} 2 \mathrm{~S}]^{1+}$ signal (measured at the $g=2.05 / 2.06$ peak) versus sample potential $(E)$ were fitted a form of the $n=1$ Nernst equation (Hagen 2008).

$$
[\mathrm{Red}]=\frac{[\mathrm{Ox}]+[\mathrm{Red}]}{1+\exp \left(\left(E-E_{\mathrm{m}}\right) / 0.026\right.}
$$

Fits were carried out using the nonlinear least-squares curve fitter in OriginPro. Errors in the $E_{\mathrm{m}}$ values are estimated at $\pm 6 \mathrm{mV}$ from the standard error of the fits and voltage readouts during the experiment.

\section{Results}

\section{Crystal structure of CrFDX2}

The structure of $\mathrm{CrFDX} 2$ was refined to a resolution of $1.18 \AA$ with $\mathrm{R}$ and Rfree of 0.109 and 0.147 , respectively (Fig. 1). There is only one molecule in the asymmetric unit in complex with the [2Fe2S] cluster (Fig. 1a), and it shows a typical ferredoxin fold with a $\beta$-sheet formed by five $\beta$ strands covered by a single $\alpha$-helix (Fukuyama 2004). The [2Fe2S] cluster of $\mathrm{CrFDX} 2$ is coordinated by four cysteine 

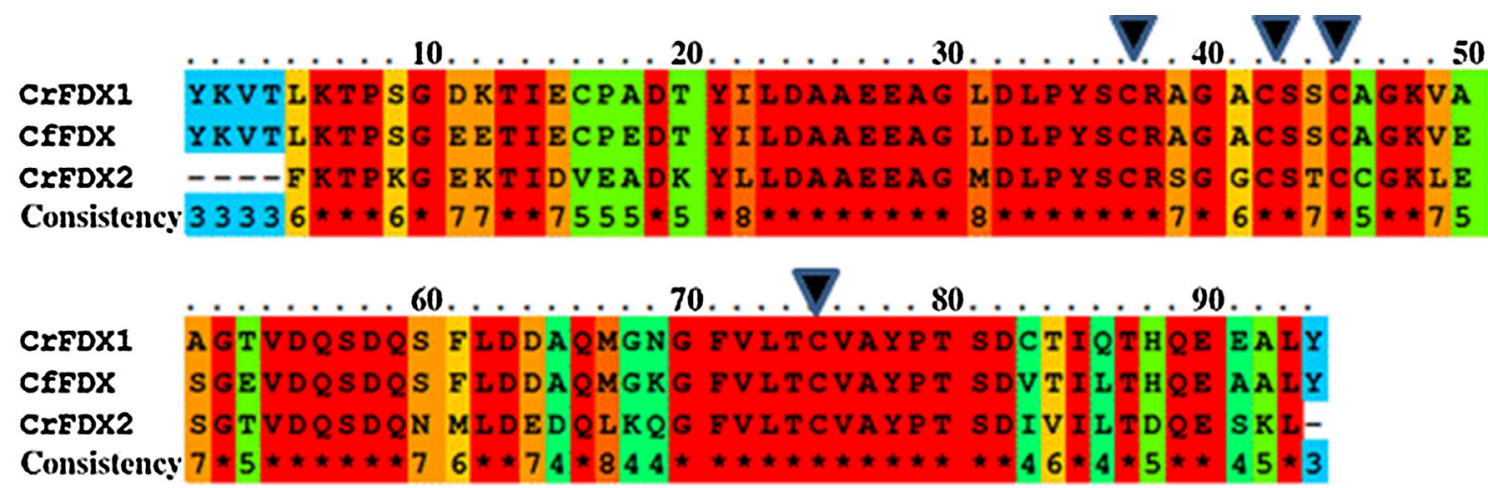

\section{Unconserved 012345678910 Conserved}

Fig. 3 Protein sequence alignment for $C r F D X 1, C r F D X 2$, and $C f$ FDX. The protein sequences of the mature $C r$ FDX1, $C r F D X 2$ and $C f F D X$ proteins were aligned using the Praline multiple sequence alignment tool (http://www.ibi.vu.nl/programs/pralinewww/), and they highlight amino acid conservation among the three proteins (the

residues: Cys38, Cys 43, Cys 46, and Cys 76 (Fig. 2a, b; the numbering differs from that in Fig. 3 by 1, due to the lack of $\mathrm{M}$ at the start of each recombinant protein sequence). This structure has been deposited into the protein data bank (PDB; www.rcsb.org) with entry code 4ITK.

\section{Structural comparison with other FDXs}

Pair-wise secondary structure matching by the PDB-fold program (Krissinel and Henrick 2004) found 60 unique structural matches for $\mathrm{CrFDX} 2$ from the protein data bank with at least $70 \%$ secondary structure similarity. Out of these, the first 53 were $[2 \mathrm{Fe} 2 \mathrm{~S}]-$ ferredoxins and the remaining 7 , although having high protein fold similarity to $\mathrm{CrFDX} 2$, showed less than $20 \%$ sequence similarity with it. The most similar match to $\mathrm{CrFDX} 2$ was the cyanobacterium Mastigocladus laminosus [2Fe2S]-FDX (PDB ID: 1RFK; (Fish et al. 2005)), with a secondary structure similarity of $100 \%$, sequence similarity of $66 \%$, and $\mathrm{C} \alpha$ root mean square deviation of $0.84 \AA^{2}$, suggesting similar backbones between the two proteins. Further inspections of similar ferredoxin structures showed significant variability between the positions of the backbone atoms away from the iron-sulfur cluster. This was the case even when the overall structure seemed to be highly similar. To properly find similar structures that might have been missed by the structural similarity search, we searched the PDB using sequence homology with the ICM program and found 36 structures with sequence similarity above $25 \%$. The best hit was Chlorella fusca FDX1 (CfFDX1, PDB ID: 1AWD Bes et al. 1999) with sequence similarity of $68 \%$ and $\mathrm{C} \alpha$ root mean square deviation of $0.79 \AA^{2}$. Closer inspection of three sequences show $75 \%$ similarities). The arrowheads indicate the [2Fe2S]-cluster coordinating cysteine residues C37, C42, C45, and C75. All numbering differs by 1 due to the lack of the $\mathrm{M}$ at the start, which is present in the recombinant protein of the CrFDXs

this structure showed that it indeed was highly similar to CrFDX2.

\section{Algal CrFDX1/CrFDX2 binding interface with CrHYDA1/CrFNR1 and point mutations}

The $C r F D X 1$ and $C r F D X 2$ proteins are highly homologous, with $67 \%$ sequence identity (Fig. 3). Furthermore, CrFDX2 (a root-type ferredoxin Terauchi et al. 2009) shares a practically identical protein backbone with the leaf-type $C f F D X 1$ (Fig. 3) indicating that both FDX types would be expected to share the same binding interface with $C r$ HYDA1/CrFNR1 (Fig. 2a). For this interaction, we assumed that the binding interface is centered on the ironsulfur cluster, based on a thorough analysis of related binding interfaces from literature (Chang et al. 2007; Hurley et al. 1993a, b; Morales et al. 2000). The distance between the iron-sulfur clusters is crucial for electron tunneling. According to known structures and computer modeling of electron tunneling enzyme complexes, the edge-to-edge distances should not exceed $14 \AA$ in the absence of other additional cofactors to act as electron relays. This is the maximum distance that allows for physiologically relevant electron-transfer rates (Moser et al. 2010; Page et al. 1999; Gray and Winkler 1996). Using this information, we visually identified residues in the vicinity of the iron-sulfur cluster that were conserved between $C r F D X 1$ and $C f F D X 1$ but not in $C r F D X 2$. We specifically focused on two amino acids located near the electron acceptor site of FDX1, namely F62 and Y95: (Fig. $2 \mathrm{~b}$ shows the location of these residues). 


\section{In vitro hydrogen photo-production rate}

To evaluate the effect of the selected mutated amino acid residues on $C r F D X 2$ biochemical properties, we measured hydrogen photo-production rates driven by $C r F D X 1$, $\mathrm{CrFDX} 2$, and the point-mutated versions of $\mathrm{CrFDX} 2$ (M62F, $\nabla 95 \mathrm{Y}$, and M62F/ $795 \mathrm{Y}$ ) (see Table 2). In agreement with Peden et al. (2013), CrFDX1 promoted the highest hydrogen photo-production rate, $489( \pm 48) \mu \mathrm{mol}$ $\mathrm{H}_{2} \mu \mathrm{g} \mathrm{Chl}^{-1} \mathrm{~h}^{-1}$, while $\mathrm{CrFDX} 2$ displayed a 5.6-fold lower rate $\left(86 \pm 11 \mu \mathrm{mol} \mathrm{H} \mathrm{H}_{2} \mu \mathrm{ghl}^{-1} \mathrm{~h}^{-1}\right)$. Interestingly, each of the $C r F D X 2$ point-mutants resulted in rates that were almost twofold higher than the native CrFDX2 (M62F, $150 \pm 41$; and $\nabla 95 \mathrm{Y}, 134 \pm 42 \mu \mathrm{mol} \mathrm{H}_{2} \mu \mathrm{g}$ $\mathrm{Chl}^{-1} \mathrm{~h}^{-1}$ ), but lower than the CrFDX1 rates. This effect appears to be additive, as the CrFDX2 double mutant (M62F/ $\nabla 95 \mathrm{Y})$ displayed the highest rate among the three mutants $\left(264 \pm 69 \mu \mathrm{mol} \mathrm{H}{ }_{2} \mu \mathrm{g} \mathrm{Chl}^{-1} \mathrm{~h}^{-1}\right)$. The HYDA1 $\mathrm{H}_{2}$ evolution rate with $C r \mathrm{FDX} 2 \mathrm{M} 62 \mathrm{~F} / \nabla 95 \mathrm{Y}$ was threefold higher than with $C r F D X 2 \mathrm{WT}$, and half of that with CrFDX1. These data show that F62 and Y95 each function to support productive electron-transfer complexes between CrFDX1 and CrHYDA1 and, when engineered onto $C r F D X 2$, confer it higher catalytic rates. In other words, mutations that introduce these $C r F D X 1$ amino acid residues onto $C r F D X 2$ are likely to induce similar structural changes in $\mathrm{CrFDX} 2$ to promote higher hydrogen production rates, closer to those measured with $C r$ HYDA1.

\section{In vitro NADPH photo-production kinetic parameters}

The kinetic parameters $K_{\mathrm{m}}(\mu \mathrm{M}), V_{\max }(\mu \mathrm{mol}$ NADPH $\mu \mathrm{g}$ $\left.\mathrm{Chl}^{-1} \mathrm{~h}^{-1}\right)$ and $k_{\text {cat }}\left(\mathrm{s}^{-1}\right)$, of $C r F D X 1, C r F D X 2$, and the CrFDX2 point-mutants for the NADPH photo-production reaction were determined from the respective LineweaverBurk plots (see Table 3 and Supplemental Fig. 5). Interestingly, the $V_{\max }$ values for NADPH photo-production were similar for $C r F D X 1$ and $C r F D X 2$, at $185( \pm 68)$ and
177 ( \pm 47$) \mu \mathrm{mol} \mathrm{NADPH} \mu \mathrm{g} \mathrm{Chl} \mathrm{Ch}^{-1} \mathrm{~h}^{-1}$, respectively. However, the $K_{\mathrm{m}}$ for $C r F D X 2(0.18 \pm 0.01, \mu \mathrm{M})$ was significantly lower than that for $C r F D X 1 \quad(0.40 \pm 0.04$, $\mu \mathrm{M})$, indicating $C r \mathrm{FDX} 2^{\prime}$ s higher affinity for $C r \mathrm{FNR} 1$. On the other hand, $K_{\mathrm{m}}$ values for each of the $C r F D X 2$ mutants were higher than that for the native CrFDX2 (Table 3), with values of $0.69 \pm 0.04 \mu \mathrm{M}$ for the M62F mutant, $0.38 \pm 0.03 \mu \mathrm{M}$ for the $\nabla 95 \mathrm{Y}$ mutant, and $3.44 \pm 0.71$ $\mu \mathrm{M}$ for the $\mathrm{M} 62 \mathrm{~F} / \nabla 95 \mathrm{Y}$ double mutant. The calculated $V_{\text {max }}$ values for the FNR-catalyzed NADPH production by the mutant proteins were $161 \pm 26 \mu$ mol NADPH $\mu \mathrm{g}$ $\mathrm{Chl}^{-1} \mathrm{~h}^{-1}$ for the M62F mutant, $202 \pm 10 \mu \mathrm{mol}$ NADPH $\mu \mathrm{g} \quad \mathrm{Chl}^{-1} \mathrm{~h}^{-1}$ for the $\nabla 95 \mathrm{Y}$ mutant, and $260 \pm 33 \mu \mathrm{mol} \mathrm{NADPH} \mu \mathrm{g} \mathrm{Chl}{ }^{-1} \mathrm{~h}^{-1}$ for the M62F/ $\nabla 95 \mathrm{Y}$ double mutant. These values are very similar to those measured with either $C r F D X 1$ or $C r F D X 2$ WT proteins, considering the error bars. The catalytic efficiencies of $\mathrm{CrFDX} 2$ and $\mathrm{CrFDX} 2$ mutants in driving the $C r F N R 1-d e-$ pendent reaction, $k_{\text {cat }} / K_{\mathrm{m}}$, showed interesting trends compared to $C r F D X 1$ (Table 3). Although $C r F D X 2$ supported a slightly lower $V_{\text {max }}$, the lower $K_{\mathrm{m}}$ with $C r F N R 1$ resulted in a twofold larger $k_{\text {cat }} / K_{\mathrm{m}}$, indicating the formation of a more efficient catalytic complex. On the other hand, $C r F D X 2$ M62F presented a fourfold lower $k_{\text {cat }} / K_{\mathrm{m}}$ compared to $C r F D X 2$ and twofold lower than $C r F D X 1$. The $C r F D X 2$ $\nabla 95 \mathrm{Y}$ variant led to a slightly higher $V_{\max }$ but lower $k_{\mathrm{cat}} / K_{\mathrm{m}}$, a value that is more similar to that measured with $C r F D X 1$. When the M62F mutation was paired with $\nabla 95 \mathrm{Y}$ in the $C r F D X 2$ double mutant, the resulting variant supported the highest $k_{\text {cat }}$, but led to a large, 13 -fold decrease in $k_{\text {cat }} / K_{\mathrm{m}}$ compared to $C r F D X 2$. Overall, the kinetics suggest that $C r F D X 2$, under growth conditions where it is present in equimolar amounts to $C r F D X 1$, is better at electron transfer with FNR1 than $C r F D X 1$, by virtue of forming a more efficient catalytic complex with FNR1. In contrast, $C r F D X 1$ catalyzes higher rates of $\mathrm{H}_{2}$ evolution, and the changes (although small) observed with the M62F and $895 \mathrm{Y}$ mutants of $\mathrm{CrFDX} 2$ are evidence for involvement of these residues in $\mathrm{H}_{2}$ evolution.
Table 2 Hydrogen photoproduction rates

\begin{tabular}{lc}
\hline Ferredoxin & $\begin{array}{c}\text { Hydrogen Photo-production } \\
\text { Rate }\left(\mu \mathrm{mol} \mathrm{H}_{2} \mu \mathrm{Ch}^{-1} \mathrm{~h}^{-1}\right)\end{array}$ \\
\hline$C r$ FDX1 & $489 \pm 48$ \\
$C r$ FDX2 & $86 \pm 11$ \\
$C r F D X 2(\mathrm{M} 62 \mathrm{~F})$ & $150 \pm 41$ \\
$C r \mathrm{FDX} 2(\nabla 95 \mathrm{Y})$ & $134 \pm 42$ \\
$C r \mathrm{FDX} 2(\mathrm{M} 62 \mathrm{~F} / \nabla 95 \mathrm{Y})$ & $264 \pm 69$ \\
\hline
\end{tabular}

The $C r \mathrm{FDX} 1, C r \mathrm{FDX} 2$, and mutated $C r \mathrm{FDX} 2$ proteins used for the hydrogen photo-production assay were the cleaved forms purified from proteins over-expressed in E. coli from the respective FDX-TEVcs-GSTHis constructs. Individual rates were calculated from four time points (approximately $t=60,180,300$ and $420 \mathrm{~min}$ ) and the averaged rates are shown 
Table 3 Kinetic values for FDX-mediated NADPH photo-production in a reconstituted system

\begin{tabular}{|c|c|c|c|c|}
\hline Ferredoxin & $K_{\mathrm{m}} \mathrm{NADP}^{+}(\mu \mathrm{M})$ & $\begin{array}{l}V_{\max } \mathrm{NADP}^{+} \\
\left(\mu \mathrm{mol} \text { NADPH } \mu \mathrm{ghl}^{-1} \mathrm{~h}^{-1}\right)\end{array}$ & $\begin{array}{l}\text { Turnover } k_{\mathrm{cat}}\left(\mathrm{s}^{-1}\right) \\
\text { for } \mathrm{NADP}^{+} \text {reduction }\end{array}$ & $\begin{array}{l}\text { Efficiency } k_{\mathrm{cat}} / K_{\mathrm{m}}\left(\mathrm{M}^{-1} \mathrm{~s}^{-1}\right) \\
\text { for NADP }{ }^{+} \text {reduction }\end{array}$ \\
\hline$C r F D X 1$ & $0.40 \pm 0.04$ & $185 \pm 68$ & $668 \pm 25$ & $17 \times 10^{8}$ \\
\hline$C r \mathrm{FDX} 2$ & $0.18 \pm 0.01$ & $177 \pm 47$ & $638 \pm 17$ & $35 \times 10^{8}$ \\
\hline CrFDX2 (M62F) & $0.69 \pm 0.04$ & $161 \pm 26$ & $581 \pm 9$ & $8.4 \times 10^{8}$ \\
\hline$C r F D X 2(\nabla 95 \mathrm{Y})$ & $0.38 \pm 0.03$ & $202 \pm 10$ & $729 \pm 37$ & $19 \times 10^{8}$ \\
\hline CrFDX2 (M62F/ $795 \mathrm{Y})$ & $3.44 \pm 0.71$ & $260 \pm 33$ & $939 \pm 120$ & $2.7 \times 10^{8}$ \\
\hline
\end{tabular}

The FDX1, FDX2, and mutated FDX2 proteins used for the NADPH photo-production assay were prepared by TEV treatment of FDX-TEVcsGST-His fusions. Both $K_{\mathrm{m}}$ and $V_{\max }$ values were calculated from three independent replicates using linear regression analyses of LineweaverBurk plots. Supplemental Fig. 5 shows the Lineweaver-Burk plots for the averaged rates. NADPH photo-production rates $\left(V_{\max }\right)$ are given in $\mu \mathrm{mol}$ NADPH $\mu \mathrm{g} \mathrm{Chl}^{-1} \mathrm{~h}^{-1}$ with $1 \mathrm{mM}$ FNR1 present and a $1-\mathrm{ml}$ assay volume were calculated from the initial 15 min after mixing. The $k_{\text {cat }}$ values were calculated at FDX concentrations of $1 \mathrm{mM}$

\section{Midpoint redox potential determination}

The midpoint redox potentials of the $\mathrm{CrFDX} 2$ mutants were determined to test the effect of the mutations on the electron transfer properties of the $[2 \mathrm{Fe} 2 \mathrm{~S}]$ cluster. Both of the single mutations shifted the potential more negative compared to $\mathrm{CrFDX} 2$, with the M62F mutation giving the largest shift bringing it close to the midpoint potential of CrFDX1 (Fig. 4, Table 4). Surprisingly, the double mutant did not show an additive shift of the single mutations but rather displayed a redox potential similar to that of the $\nabla 95 \mathrm{Y}$ alone. While the overall rhombic signal assigned to the $[2 \mathrm{Fe} 2 \mathrm{~S}]$ cluster was almost identical in all cases, slight shifts in the $g$-values were observed for the mutants. It should be noted that appearance of other small signals were observed; however, these are likely from the redox cocktail and formation of radical species during the course of reduction with NaDT. The shifts in the rhombic [2Fe2S]cluster signal can be summarized by a subtle upfield energy shift from the $g$-values of $\mathrm{CrFDX} 2(g=2.06,1.97$, and $1.88)$ to the $g$-values of $C r F D X 1 \quad(g=2.05,1.96$, and 1.88). Compared to $\nabla 95 \mathrm{Y}$ ( $g=2.063,1.973$, and 1.883) and $\mathrm{M} 62 \mathrm{~F} / \nabla 95 \mathrm{Y}(g=2.060,1.969$, and 1.883$)$, M62 showed the largest shift $(g=2.052,1.959$, and 1.880) resulting in its overall signal to more closely align with CrFDX1 (Fig. 4 inset). Interestingly, these trends match nicely to the midpoint potential shifts of the mutants and particularly for M62F may indicate an underlying role toward finely tuning the orientation and electronic properties of the cluster.

\section{Discussion}

Recently, we initiated efforts to fully characterize the Chlamydomonas FDX interaction network (Peden et al. 2013). We and others had shown previously that $C r$ FDX1 plays a predominant role as an electron carrier in the cell, through electron-transfer and binding interactions with multiple partners (Noth et al. 2012; Peden et al. 2013; Terauchi et al. 2009; van Lis et al. 2013). Interestingly, CrFDX2 was demonstrated to be capable of binding in vitro to some of the same electron partners and promoting similar redox reactions as $C r F D X 1$ (Noth et al. 2012; Peden et al. 2013; van Lis et al. 2013).

In order to determine and compare the characteristics and functions of the two $\mathrm{CrFDXs}$ in more details, and to identify and study the nature of their interaction with other enzymes, we performed additional biochemical and biophysical assays on the two-purified proteins. The spectroscopy studies confirmed that both proteins are highly similar, showing typical [2Fe2S]-ferredoxin spectra (Supplemental Figs. 2, 3, and 4). We also grew crystals and solved the $C r F D X 2$ structure, which represents the first solved Chlamydomonas FDX structure. A structure of CrFDX1 from Chlorella fusca was previously reported (Bes et al. 1999), and it was used for the visual identification of differences between $C r F D X 1$ and $C r F D X 2$. Five different amino acids located in the vicinity of the [2Fe2S] cluster and at the binding interface between both $\mathrm{CrFDXs}$ and $\mathrm{CrHYDA} 1$ were identified (Winkler et al. 2009a). As such, they have the potential to affect the binding properties of either of the two $\mathrm{CrFDXs}$, or possibly their electron transfer potentials to specific donors/acceptors. We mutated two residues in $\mathrm{CrFDX} 2$ to resemble those present in $C r$ FDX1 and determined the effects on two reactions: $\mathrm{NADP}^{+}$reduction and $\mathrm{H}_{2}$ photo-production.

The catalytic properties of each of our FDX mutants are different with respect to electron transport to $C r$ HYDA1 and $C r$ FNR1, as shown in Tables 2 and 3, respectively. We demonstrated that introduction of Y95 and mutation of CrFDX2 M62 to phenylalanine directly affects its hydrogen and NADPH photo-production activity. The single $C r$ FDX2 M62F and $\nabla 95 \mathrm{Y}$ mutants showed higher hydrogen photo-production rates than the $C r F D X 2$ WT protein, but not as high as that of $\mathrm{CrFDX} 1$. This demonstrates that 


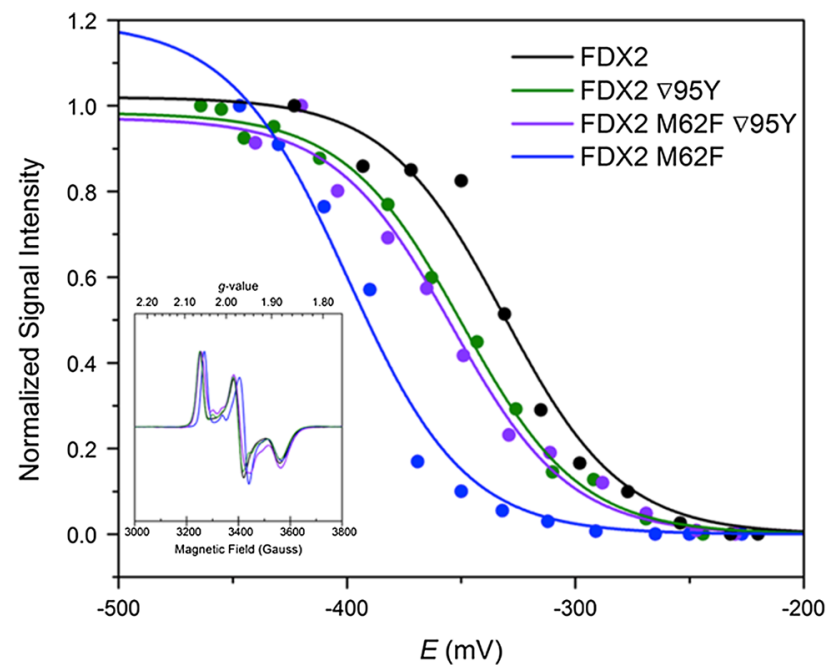

Fig. 4 Redox titrations of the [2Fe2S]-EPR signal (inset) from reduced $C r \mathrm{FDX} 2$ wild type, $\nabla 95 \mathrm{Y}, \mathrm{M} 62 \mathrm{~F} / \nabla 95 \mathrm{Y}$, and M62F mutants. Each point reflects a measured EPR amplitude of the $g=2.05 / 2.06$ peak for individual samples poised at particular potentials $(E)$ vs NHE. The midpoint potentials were determined by fitting the potentiometric curves to the $n=1$ electron form of the Nernst Equation

Table 4 The midpoint potentials of FDX2 mutants compared to $\mathrm{CrFDX} 1$ and $\mathrm{CrFDX} 2$ wild types

\begin{tabular}{ll}
\hline Ferredoxin & $E_{\mathrm{m}}(\mathrm{vs} \mathrm{NHE})$ \\
\hline$C r F D X 1$ & $-398^{\mathrm{a}}$ \\
$C r F D X 2$ & $-331^{\mathrm{b}}\left(-321^{\mathrm{c}}\right)$ \\
$C r F D X 2(\mathrm{M} 62 \mathrm{~F})$ & -400 \\
$C r F D X 2(\nabla 95 \mathrm{Y})$ & -350 \\
$C r F D X 2(\mathrm{M} 62 \mathrm{~F} / \nabla 95 \mathrm{Y})$ & -356 \\
\hline
\end{tabular}

${ }^{a}$ Ref (Galván and Márquez 1985)

b This study

${ }^{c}$ Ref. (Terauchi et al. 2009)

both residues in $\mathrm{CrFDX} 1$ promote high hydrogen production, either by affecting protein complex formation/stabilization, electron transfer, or both. This was to be expected from the structural results that showed the proximity of these residues to the $C r$ FDX: $C r$ HYDA1 binding interface (Fig. 2b). Interestingly, the double mutant was able to support hydrogen production at an even higher rate than either of the two single mutants and, in fact, twofold higher than the $C r$ FDX2 WT (Table 2). The additive effect of these mutations suggests that both residues in $C r F D X 1$ contribute to its high $\mathrm{H}_{2}$ production. Indeed, both mutations resulted in shifts in the midpoint redox potentials of CrFDX2 toward more negative values (Table 4), which favor electron transfer to CrHYDA1.

We also tested the kinetics of WT and point-mutated $\mathrm{CrFDX} 2$ proteins in NADPH photo-production. We show that the presence of $\mathrm{CrFDX} 1 \mathrm{~F} 62$ and $\mathrm{Y} 95$ in $\mathrm{CrFDX} 2$ affect NADPH production in opposite manners. The presence of F62 in $\mathrm{CrFDX} 2$ interferes mostly with its binding affinity to $C r$ FNR (higher $K_{\mathrm{m}}$ compared to wild-type FDX2) and leads to a decrease in the turnover of NADPH production $\left(k_{\mathrm{cat}}\right)$. This could be due to the direct interaction between residue 62 and $C r$ FNR's FAD co-factor (Supplementary Fig. 4c, e), which may be weakened by the presence of methionine in this position. On the other hand, the deletion of Y95 from $\mathrm{CrFDX} 2$ affects all kinetic parameters of the FNR-mediated reaction, as shown by an increase in its $K_{\mathrm{m}}, \mathrm{K}_{\text {cat }}$ and catalytic efficiency (levels similar to those obtained with $C r$ FDX1) (Table 3). These residues are therefore important for the $C r F D X 1$ : $C r F N R$ interaction and photo-reduction of $\mathrm{NADP}^{+}$. It must be noted that others had shown that the $C r F N R$ has almost identical $k_{\text {cat }} s$ in the presence of either $C r F D X 1$ or $C r F D X 2$, but the $K_{\mathrm{m}}$ for $C r$ FDX2 was almost sixfold lower than that for $C r$ FDX1, resulting in a sixfold higher catalytic efficiency for $\mathrm{CrFDX} 2$ (Hurley et al. 1997; Vieira and Davis 1986). However, the reported values were derived from an assay that indirectly measured electron transfer between ferredoxin and $\mathrm{CrFNR}$ using cytochrome c reductase activity; therefore their results are not directly comparable to ours.

The kinetics parameters observed for the $\mathrm{CrFDX} 2$ double mutant seem to be a combined effect of the two single mutations, yielding a protein with a much higher $K_{\mathrm{m}}$ (as the single M62F mutant), but also high $V_{\max }$ (high rates of NADP reduction, as the single $\nabla 95 \mathrm{Y}$ mutant) and high $k_{\text {cat }}$ (higher catalytic efficiency, as the single $\nabla 95 \mathrm{Y}$ mutant), although low catalytic efficiency. These differences are accompanied by structural differences at positions 62 and 95 in the $C r F D X s$, which could partially account for the observed differences in kinetics. These observations are also consistent with the concept that subtle changes involving this particular structural region have significant effects in electron transfer within the functional catalytic complex. Indeed, all the mutations introduced at position 62 and 95 of $\mathrm{CrFDX} 2$, singly or in combination led to changes in redox-midpoint potentials as compared to $\mathrm{Cr}$ FDX2.The EPR titration data (Table 4) showed that the $E_{\mathrm{m}}$ value of the $\nabla 95 \mathrm{Y} C r \mathrm{FDX} 2$ mutant shifted more negatively, closer to the $C r$ FDX1 value ( -350 vs -398 vs $-331 \mathrm{mV}$ for $\nabla 95 \mathrm{Y}, C r \mathrm{FDX} 1$ and $C r \mathrm{FDX} 2$, respectively). The double mutant M62F/ $\nabla 95 \mathrm{Y}$ showed a similar pattern with an $E_{m}$ of $-350 \mathrm{mV}$ where the single M62F mutant had midpoint potential of $-400 \mathrm{mV}$ almost identical to CrFDX1 (-398 mV Terauchi et al. 2009).

In previous literature, certain amino acid residues were shown to be important specifically for the CrFDX1/ CrHYDA1 interaction, and to be critical for efficient electron transfer between these two proteins. In silico docking analysis and site-directed mutagenesis, for 
instance, identified (among ten amino acid residues tested) CrHYDA1 K396, and FDX1 E122 (amino acid numbers represent the position in the protein prior to cleavage of the transit peptide) as the major contributors to the formation of the FDX-HYD1 complex (Winkler et al. 2010). Interestingly, the two CrHYDA1 and CrHYDA2 share conservation of the required lysine, and five $C r F D X s$ (except for CrFDX3) contain the conserved glutamic acid residue. Residues D56 and F93 in FDX1 were also shown to be important for the CrFDX1-CrHYDA1 interaction; F93 together with E122 and Y126 was proposed to be involved in stabilizing the redox state of [2Fe2S] cluster of $\mathrm{CrFDX} 1$, suggesting their probable role in electron transfer between CrFDX1 and CrHYDA1 (Winkler et al. 2010). Indeed, when mutated to nonconserved residues, the respective recombinant proteins showed a decreased $V_{\max }$ for $\mathrm{H}_{2}$ photo-production of more than threefold compared to the WT value (11).

Electrostatic interactions have also been demonstrated to be crucial for the interaction between ferredoxins and all their other target enzymes, such as FNR, FD:thioredoxins reductase, nitrite reductase, glutamate synthase, and sulfite reductase (Hanke and Mulo 2013). More specifically, CrFDX1 interaction-complex studies have provided evidence for the essential role of another conserved glutamate, E91, located in the short C-terminal tail of CrFDX1, and of a negatively charged patch, located in its most N-terminal a1-helix, which includes D25, E28, and E29. All four negatively charged residues are conserved only in CrFDX1, CrFDX2, and CrFDX5, out of the six CrFDXs (Terauchi et al. 2009). E91 is involved in forming complexes with nitrite reductase $(\mathrm{NiR})$, glutamate synthetase (FDX-GOGAT), and the photosystem I subunit C (PSAC). Mutations of this residue in $C r F D X 1$ diminish its catalytic activity in the reactions involving these enzymes (Fischer et al. 1998; GarciaSanchez et al. 1997). In addition, a triple D25A/E28Q/E29Q mutant protein showed less efficient interaction with those same three interacting enzymes (GarciaSanchez et al. 1997; Jacquot et al. 1997).

Besides electrostatic interactions, the midpoint redox potential of the two $C r F D X s$ plays an important role in their physiological functions. Normally, CrFDX2 catalyzes nitrite reduction (Terauchi et al. 2009), a reaction with a midpoint redox potential of about $-300 \mathrm{mV}$; $\mathrm{NADP}^{+}$ reduction and $\mathrm{H}_{2}$ production, on the other hand, are catalyzed by $C r F D X 1$ in vivo, in reactions that require more negative redox potentials $(-320$ and $-400 \mathrm{mV}$, respectively). It was shown that the presence of an aromatic residue at position 65 in Anabaena ferredoxin is essential for effective electron transfer with FNR (Hurley, cheng et al. 1993), and that natural variants of animal and bacterial FDXs in which methionine is replaced by phenylalanine show a shift in the $E_{\mathrm{m}}$ to more positive values
(Hurley et al. 1993a, b, 1997). We suspected that the switch from phenylalanine at residue 62 in $C r F D X 1$ to methionine in $\mathrm{CrFDX} 2$ (Fig. 2b), in particular, was responsible for the significantly different $C r$ FDX2 ability to catalyze NADPH and $\mathrm{H}_{2}$ production. In this study, we measured and compared redox potential and kinetic parameters for the $\mathrm{NADPH}$ and $\mathrm{H}_{2}$ photo-production between the $\mathrm{CrFDX} 2$ and the $C r F D X 2 \mathrm{M} 62 \mathrm{~F}$ and $\nabla 95 \mathrm{Y}$ mutants with those of CrFDX1. NADPH production, which involves $\mathrm{NADP}^{+}+2 \mathrm{H}^{+}$binding, involves a more complex reaction, since it requires the binding of both $\mathrm{NADP}^{+}$and $2 \mathrm{H}^{+}$ to the FDX/FNR complex when compared to the FDX/ HYDA interaction which requires only the binding of $2 \mathrm{H}^{+}$. Finally, although our $\mathrm{CrFDX} 2$ crystal structure shows that both residues are located near the FDX [2Fe2S] cluster and could therefore influence the catalytic activity of FDX when in complex with FNR/HYDA, it seems that this is in fact organism dependent. In Anabaena, for example, FDX undergoes a conformational change at the level of the loop that contains F65 (the equivalent of F62 in Chlamydomonas) upon binding to FNR (Morales et al. 2000). Furthermore, this amino acid is proposed to be involved in the electronic coupling between the two redox centers (Hurley et al. 1993a). On the other hand, the maize leaf FDX/FNR crystal structure complex revealed that the equivalent amino acid of F65 (here Tyr 63) is neither in close contact with the $[2 \mathrm{Fe} 2 \mathrm{~S}]$ cluster of the FDX, nor is between the two prosthetic groups from FNR (FAD) and FDX ([2Fe2S]) suggesting a different role in electron transfer to FNR for that residue (Kurisu et al. 2001). Unfortunately we do not have a crystal structure of the Chlamydomonas FDX/FNR complex to verify either mechanism. An alternative possible explanation for our kinetic data is that the mutations could interfere with PSI binding, which would further affect electron transfer to the FDXs. The data could therefore indicate that the mutations perturb the conformation of the $C r P S I$ : $C r F D X 2$ complex solely or in addition to the $\mathrm{CrFDX} 2 \mathrm{CrHYDA} 1$ complex. It is known that PSI subunits interact with $C r F D X$, although it remains unclear how many sites are present and/or available for FDX binding on CrPSI. Furthermore, no information regarding the $K_{\mathrm{m}}$ for $C r$ PSI: $C r$ FDX electron transfer is available, although $K_{\mathrm{d}}$ values for WT and some PSI mutants ranging from 6 to $0.12 \mu \mathrm{M}$ have been reported (Setif 2001; Setif et al. 2002). Finally, it must be noted that the error bars reflecting the double mutant data were particularly high, possibly due to the higher instability of the double mutant protein. The actual kinetic values must thus be taken only as representing a trend, not an actual number.

In summary, despite their high sequence similarity and comparable physical characteristics, $C r$ FDX 1 and $C r F D X 2$ also exhibit structural differences that affect their electrontransfer function. A previous structural model predicted 
differences in the surface charge distribution between the two proteins (Terauchi et al. 2009), and our $C r F D X 2$ structure and biochemical results further show that the $\mathrm{CrFDX} 2 \mathrm{M} 62$ and $\mathrm{CrFDX} 195 \mathrm{Y}$ residues make significant contributions to the binding interfaces of the respective $C r$ FDXs with $C r$ HYDA1 and $C r F N R 1$, as well as affecting their redox potentials. These distinct differences must certainly contribute to the different in vivo specificities of the two proteins (Gou et al. 2006; Terauchi et al. 2009). In this report, we indirectly demonstrate that the $C r$ FDX1 F62 and Y95 residues are important for hydrogen photo-production, as progressively increased hydrogen production rates are measured when these residues are introduced into CrFDX2. Residues F62 and Y95 also affect NADPH photo-production and have opposite impacts on the kinetic parameters of that reactions. We thus confirm that $\mathrm{CrFDX} 2$ can potentially replace $\mathrm{CrFDX} 1$ in $\mathrm{CrFDX} 1$-dependent reactions and that differences between the two proteins rely on differences between only a few amino acid residues.

Acknowledgments We acknowledge Benton Wachter for his contributions during his SULI internship at the National Renewable Energy Laboratory and ReAnna Davis for handling media preparation and protein over-expression. We also recognize Shihui Yang for help with database searches and protein annotation, as well as Prof. Sabeeha Merchant $(\alpha C r F D X 1$ and $\alpha$ FCrDX2) and Prof. Peter Nixon $(\alpha C r H Y D A)$ for generously providing us with antibodies. This research was supported by the U. S. Department of Energy, Office of Biological and Environmental Research (BER) (MLG, AD, MB, EAP); and by the U. S. Department of Energy Office of Basic Energy Sciences, Division of Chemical Sciences, Geosciences and Biosciences for EPR spectroscopy, $\mathrm{CrHYDA} 1$ expression and purification, and $C r$ FDX: $C r$ HYDA1 computational modeling (DWM, HL, and $\mathrm{PK}$ ). The CD spectroscopy and crystallization studies were funded by the Office of Energy Efficiency and Renewable Energy, Bioenergy Technology Office (BETO; MA RB and VVL).

Open Access This article is distributed under the terms of the Creative Commons Attribution 4.0 International License (http://crea tivecommons.org/licenses/by/4.0/), which permits unrestricted use, distribution, and reproduction in any medium, provided you give appropriate credit to the original author(s) and the source, provide a link to the Creative Commons license, and indicate if changes were made.

\section{References}

Bertini I, Luchinat C, Provenzani A, Rosato A, Vasos PR (2002) Browsing gene banks for $\mathrm{Fe} 2 \mathrm{~S} 2$ ferredoxins and structural modeling of 88 plant-type sequences: an analysis of fold and function. Proteins 46:110-127

Bes MT, Parisini E, Inda LA, Saraiva LM, Peleato ML, Sheldrick GM (1999) Crystal structure determination at 1.4 A resolution of ferredoxin from the green alga Chlorella fusca. Structure 7:1201-1211 (London, England : 1993)

Chang CH, King PW, Ghirardi ML, Kim K (2007) Atomic resolution Modeling of the ferredoxin: $\mathrm{FeFe}$ hydrogenase complex from Chlamydomonas reinhardtii. Biophys J 93:3034-3045
Chen VB, Arendall WB 3rd, Headd JJ, Keedy DA, Immormino RM, Kapral GJ, Murray LW, Richardson JS, Richardson DC (2010a) MolProbity: all-atom structure validation for macromolecular crystallography. Acta Crystallogr D Biol Crystallogr 66:12-21

Chen VB, Arendall WB III, Headd JJ, Keedy DA, Immormino RM, Kapral GJ, Murray LW, Richardson JS, Richardson DC (2010b) MolProbity: all-atom structure validation for macromolecular crystallography. Acta Crystallogr Sect D Biol Crystallogr 66:12-21

Dutton PL (1978) Redox potentiometry: determination of midpoint potentials of oxidation-reduction components of biological electron-transfer systems. Methods Enzymol 54:411-435

Emsley P, Lohkamp B, Scott WG, Cowtan K (2010) Features and development of Coot. Acta Crystallogr D Biol Crystallogr 66:486-501

Engh RA, Huber R (1991) Accurate bond and angle parameters for $\mathrm{X}$-Ray protein-structure refinement. Acta Crystallogr Sect A 47:392-400

Fischer N, Hippler M, Setif P, Jacquot JP, Rochaix JD (1998) The PsaC subunit of photosystem I provides an essential lysine residue for fast electron transfer to ferredoxin. EMBO J $17: 849-858$

Fish A, Danieli T, Ohad I, Nechushtai R, Livnah O (2005) Structural basis for the thermostability of ferredoxin from the cyanobacterium Mastigocladus laminosus. J Mol Biol 350:599-608

Fukuyama K (2004) Structure and function of plant-type ferredoxins. Photosynth Res 81:289-301

Galván F, Márquez A (1985) Physicochemical properties of ferredoxin from Chlamydomonas reinhardii. Zeitschrift fur Naturforschung. Sect C Biosci 40:373-378

GarciaSanchez MI, Gotor C, Jacquot JP, Stein M, Suzuki A, Vega JM (1997) Critical residues of Chlamydomonas reinhardtii ferredoxin for interaction with nitrite reductase and glutamate synthase revealed by site-directed mutagenesis. Eur J Biochem 250:364-368

Ghirardi ML, Zhang JP, Lee JW, Flynn T, Seibert M, Greenbaum E, Melis A (2000) Microalgae: a green source of renewable $\mathrm{H}_{2}$. Trends Biotechnol 18:506-511

Gou P, Hanke GT, Kimata-Ariga Y, Standley DM, Kubo A, Taniguchi I, Nakamura H, Hase T (2006) Higher order structure contributes to specific differences in redox potential and electron transfer efficiency of root and leaf ferredoxins. Biochemistry 45:14389-14396

Gray HB, Winkler JR (1996) Electron transfer in proteins. Annual Review of Biochemistry 65:537-561

Hagen WR (2008) Biomolecular EPR spectroscopy. CRC press ISBN 978-1-4200-5957-1

Hanke G, Mulo P (2013) Plant type ferredoxins and ferredoxindependent metabolism. Plant Cell Environ 36:1071-1084

Harris EH (2009) The Chlamydomonas sourcebook, 2nd edn., Introduction to Chlamydomonas and its laboratory use, vol 2, Chap 7Academic Press, Oxford, pp 217-255

Hase T, Wada K, Matsubara H (1976) Amino-acid sequence of major component of aphanothece-sacrum ferredoxin. J Biochem 79:329-343

Hurley JK, Cheng H, Xia B, Markley JL, Medina M, Gomezmoreno C, Tollin G (1993a) An aromatic amino-acid is required at position 65 in Anabaena ferredoxin for rapid electron transfer to ferredoxin NADP+ reductase. J Am Chem Soc 115:1169811701

Hurley JK, Salamon Z, Meyer TE, Fitch JC, Cusanovich MA, Markley JL, Cheng H, Xia B, Chae YK, Medina M, Gomezmoreno C, Tollin G (1993b) Amino-acid residues in Anabaena ferredoxin crucial to interaction with ferredoxin NADP+ reductase site directed mutagenesis and laser flash photolysis. Biochemistry 32:9346-9354 
Hurley JK, Weber-Main AM, Stankovich MT, Benning MM, Thoden JB, Vanhooke JL, Holden HM, Chae YK, Xia B, Cheng H, Markley JL, Martinez-Julvez M, Gomez-Moreno C, Schmeits JL, Tollin G (1997) Structure-function relationships in Anabaena ferredoxin: correlations between X-ray crystal structures, reduction potentials, and rate constants of electron transfer to ferredoxin:NADP + reductase for site-specific ferredoxin mutants. Biochemistry 36:11100-11117

Hutson KG, Rogers LJ, Haslett BG, Boulter D, Cammack R (1978) Comparative studies on two ferredoxins from the cyanobacterium Nostoc strain MAC. Biochem J 172:465-477

Jacquot JP, Stein M, Suzuki A, Liottet S, Sandoz G, MiginiacMaslow M (1997) Residue Glu-91 of Chlamydomonas reinhardtii ferredoxin is essential for electron transfer to ferredoxinthioredoxin reductase. FEBS Lett 400:293-296

Kameda H, Hirabayashi K, Wada K, Fukuyama K (2011) Mapping of protein-protein interaction sites in the plant-type [2Fe-2S] ferredoxin. PLoS One 6:e21947

Kapust RB, Tozser J, Fox JD, Anderson DE, Cherry S, Copeland TD, Waugh DS (2001) Tobacco etch virus protease: mechanism of autolysis and rational design of stable mutants with wild-type catalytic proficiency. Protein Eng 14:993-1000

Krissinel E, Henrick K (2004) Secondary-structure matching (SSM), a new tool for fast protein structure alignment in three dimensions. Acta Crystallogr Sect D Biol Crystallogr 60:2256-2268

Kurisu G, Kusunoki M, Katoh E, Yamazaki T, Teshima K, Onda Y, Kimata-Ariga Y, Hase T (2001) Structure of the electron transfer complex between ferredoxin and ferredoxin-NADP $(+)$ reductase. Nat Struct Biol 8:117-121

Matsubara H, Sasaki RM (1968) Spinach ferredoxin. II tryptic, chymotryptic, and thermolytic peptides, and complete amino acid sequence. J Biol Chem 243:1732-1757

Mayoral T, Martinez-Julvez M, Perez-Dorado I, Sanz-Aparicio J, Gomez-Moreno C, Medina M, Hermoso JA (2005) Structural analysis of interactions for complex formation between Ferredoxin-NADP + reductase and its protein partners. Proteins 59:592-602

Meuser JE, D'Adamo S, Jinkerson RE, Mus F, Yang WQ, Ghirardi ML, Seibert M, Grossman AR, Posewitz MC (2012) Genetic disruption of both Chlamydomonas reinhardtii [FeFe]-hydrogenases: insight into the role of HYDA2 in $\mathrm{H}_{2}$ production. Biochem Biophys Res Commun 417:704-709

Michoux F, Takasaka K, Boehm M, Nixon PJ, Murray JW (2010) Structure of CyanoP at 2.8 A: implications for the evolution and function of the PsbP subunit of photosystem II. Biochemistry 49:7411-7413

Morales R, Charon MH, Kachalova G, Serre L, Medina M, GomezMoreno C, Frey M (2000) A redox-dependent interaction between two electron-transfer partners involved in photosynthesis. Embo Reports 1:271-276

Moser CC, Anderson JLR, Dutton PL (2010) Guidelines for tunneling in enzymes. Bba Bioenerg 1797:1573-1586

Murshudov GN, Skubak P, Lebedev AA, Pannu NS, Steiner RA, Nicholls RA, Winn MD, Long F, Vagin AA (2011) REFMAC5 for the refinement of macromolecular crystal structures. Acta Crystallogr D Biol Crystallogr 67:355-367

Noth J, Krawietz D, Hemschemeier A, Happe T (2012) Pyruvate:ferredoxin oxidoreductase is coupled to light-independent hydrogen production in Chlamydomonas reinhardtii. J Biol Chem 288(6):4368-4377
Orme-Johnson WH (1973) Iron-sulfur proteins: structure and function. Annu Rev Biochem 42:159-204

Page CC, Moser CC, Chen XX, Dutton PL (1999) Natural engineering principles of electron tunnelling in biological oxidationreduction. Nature 402:47-52

Pearson WR, Lipman DJ (1988) Improved tools for biological sequence comparison. Proc Natl Acad Sci USA 85:2444-2448

Peden EA, Boehm M, Mulder DW, Davis R, Old WM, King PW, Ghirardi ML, Dubini A (2013) Identification of global ferredoxin interaction networks in Chlamydomonas reinhardtii. J Biol Chem 288:35192-35209

Setif P (2001) Ferredoxin and flavodoxin reduction by photosystem I. Biochimica Et Biophysica Acta-Bioenerg 1507:161-179

Setif P, Fischer N, Lagoutte B, Bottin H, Rochaix JD (2002) The ferredoxin docking site of photosystem I. Biochim Et Biophys Acta-Bioenerg 1555:204-209

Stoll S, Schweiger A (2006) EasySpin, a comprehensive software package for spectral simulation and analysis in EPR. J Magn Reson 178:42-55

Terauchi AM, Lu SF, Zaffagnini M, Tappa S, Hirasawa M, Tripathy JN, Knaff DB, Farmer PJ, Lemaire SD, Hase T, Merchant SS (2009) Pattern of expression and substrate specificity of chloroplast ferredoxins from Chlamydomonas reinhardtii. J Biol Chem 284:25867-25878

Usselman RJ, Fielding AJ, Frerman FE, Watmough NJ, Eaton GR, Eaton SS (2008) Impact of mutations on the midpoint potential of the $4 \mathrm{Fe}-4 \mathrm{~S}(+1,+2)$ cluster and on catalytic activity in electron transfer flavoprotein-ubiquinone oxidoreductase (ETFQO). Biochemistry 47:92-100

Vagin A, Teplyakov A (2010) Molecular replacement with MOLREP. Acta Crystallogr D Biol Crystallogr 66:22-25

Van Lis R, Baffert C, Coute Y, Nitschke W, Atteia A (2013) Chlamydomonas reinhardtii chloroplasts contain a homodimeric pyruvate:ferredoxin oxidoreductase that functions with FDX1. Plant Physiol 161:57-71

Vieira BJ, Davis DJ (1986) Interaction of ferredoxin with ferredoxin:NADP reductase: effects of chemical modification of ferredoxin. Arch Biochem Biophys 247:140-146

Wada K, Kagamiyama H, Shin M, Matsubara H (1974) Ferredoxin from a blue-green alga, Aphanothece sacrum (Suringar) Okada. J Biochem 76:1217-1225

Winkler M, Kuhlgert S, Hippler M, Happe T (2009a) Characterization of the key step for light-driven hydrogen evolution in green algae. J Biol Chem 284:36620-36627

Winkler M, Kuhlgert S, Hippler M, Happe T (2009b) Characterization of the key step for light-driven hydrogen evolution in green algae. J Biol Chem 284:36620-36627

Winkler M, Hemschemeier A, Jacobs J, Stripp S, Happe T (2010) Multiple ferredoxin isoforms in Chlamydomonas reinhardtiitheir role under stress conditions and biotechnological implications. Eur J Cell Biol 89:998-1004

Winn MD, Ballard CC, Cowtan KD, Dodson EJ, Emsley P, Evans PR, Keegan RM, Krissinel EB, Leslie AG, McCoy A, McNicholas SJ, Murshudov GN, Pannu NS, Potterton EA, Powell HR, Read RJ, Vagin A, Wilson KS (2011) Overview of the CCP4 suite and current developments. Acta Crystallogr Sect D Biol Crystallogr 67:235-242

Yacoby I, Tegler LT, Pochekailov S, Zhang S, King PW (2012) Optimized expression and purification for high-activity preparations of algal [FeFe]-hydrogenase. PLoS ONE 7:e35886 